\title{
Increase in hospital admission rates for heart failure in the Netherlands, 1980-1993
}

\author{
J B Reitsma, A Mosterd, A J M de Craen, R W Koster, F J L van Capelle, D E Grobbee, \\ J G P Tijssen
}

Department of Clinical Epidemiology and Biostatistics,

Academic Medical Centre, University of Amsterdam, The Netherlands

J B Reitsma

A J M de Craen

J G P Tijssen

Department of Cardiology, Academic

Medical Centre,

University of

Amsterdam, The

Netherlands

R W Koster

F J L van Capelle

Department of

Epidemiology and

Biostatistics, Erasmus

University Medical

School, Rotterdam,

The Netherlands

A Mosterd

D E Grobbee

Correspondence to:

Dr J B Reitsma, Department

of Clinical Epidemiology

and Biostatistics, Academic

Medical Centre, University

of Amsterdam, PO Box

22700, $1100 \mathrm{DE}$

Amsterdam, The

Netherlands.

Accepted for publication

5 June 1996

\begin{abstract}
Objective-To study the trend in hospital admission rates for heart failure in the Netherlands from 1980 to 1993.

Design-All hospital admissions in the Netherlands with a principal discharge diagnosis of heart failure were analysed. In addition, individual records of heart failure patients from a subset of 7 hospitals were analysed to estimate the frequency and timing of readmissions.

Results-The total number of discharges for men increased from 7377 in 1980 to 13022 in 1993, and for women from 7064 to 12944 . From 1980 through 1993 age adjusted discharge rates rose $48 \%$ for men and $40 \%$ for women. Age adjusted inhospital mortality for heart failure decreased from $19 \%$ in 1980 to $15 \%$ in 1993. For all age groups in-hospital mortality for men was higher than for women. The mean length of hospital admissions in 1993 was 14.0 days for men and 16.4 days for women. A review of individual patient records from a $6 \cdot 3 \%$ sample of all hospital admissions in the Netherlands indicated that within a 2 year period $18 \%$ of the heart failure patients were admitted more than once and $5 \%$ more than twice.

Conclusions-For both men and women a pronounced increase in age adjusted discharge rates for heart failure was observed in the Netherlands from 1980 to 1993. Readmissions were a prominent feature among heart failure patients. Higher survival rates after acute myocardial infarction and the longer survival of patients with heart disease, including heart failure may have contributed to the observed increase. The importance of advances in diagnostic tools and of possible changes in admission policy remain uncertain.
\end{abstract}

(Heart 1996;76:388-392)

Keywords: heart failure; hospital discharges; time trends; Netherlands

Heart failure is a complex clinical syndrome representing a common and important health problem. ${ }^{1}$ In 1988 the direct medical costs of heart failure in the Netherlands were estimated at $£ 182$ million, corresponding to $1 \%$ of the total health care budget for that year. ${ }^{2}$ The prognosis of a patient with heart failure is poor. In the Framingham heart study $75 \%$ of men and $60 \%$ of women died within five years after the diagnosis of heart failure. ${ }^{3}$ Despite its importance, reliable estimates of the incidence and prevalence of heart failure in the general population are surprisingly scarce. This may be attributed to the atypical symptoms of the early stages of heart failure, the ongoing debate on the definition of heart failure, and the lack of a gold standard to assess the presence of heart failure. ${ }^{4}$ Hospital based registries provide some insight into the occurrence of heart failure in the population. Increases in age adjusted discharge rates for heart failure in the United States, Sweden, and Scotland have been reported in recent years..$^{5-8}$ A recently developed model predicts a further increase in the number of heart failure patients in the Netherlands in the coming decades. ${ }^{9}$ We describe the trend in hospital admissions for heart failure in the Netherlands from 1980 to 1993. Furthermore, we assessed the frequency and timing of readmissions for heart failure during a two year period in a subset of seven hospitals.

\section{Patients and methods}

Population figures were obtained from the office of Statistics Netherlands, Voorburg, the Netherlands. The number of hospital discharges for heart failure by five year age groups were derived from the National Medical Register of SIG Health Care Information, Utrecht, the Netherlands. From 1986 onwards all hospitals (university and general) in the Netherlands participated in this register. In 1980 , the starting year of our analysis, $95 \%$ of all hospital admissions in the Netherlands were recorded. Based on this coverage we used appropriate multiplying factors to estimate the yearly number of hospital discharges in the Netherlands before 1986. All records contain a principal diagnosis coded according to International Classification of Diseases Clinical Modification (9th revision), ${ }^{10}$ age and gender of the patient, status at discharge (dead or alive), and length of stay. We used the following codes to identify discharges for heart failure: heart failure (428.x), hypertensive heart disease (402.x), and myocardial degeneration $(429 \cdot 1)$. Only admissions with a first-listed (principal, main) discharge diagnosis of heart failure were included in this analysis. Inhospital mortality (as a percentage) was calculated by dividing the number of hospital admissions with a discharge status of dead by the total number of hospital admissions for heart failure. 
Table 1 Number of hospital discharges for heart failure, mean length of stay, and mean age at admission in the Netherlands from 1980 through 1993

\begin{tabular}{|c|c|c|c|c|c|c|}
\hline \multirow[b]{2}{*}{ Year } & \multicolumn{3}{|l|}{ Men } & \multicolumn{3}{|l|}{ Women } \\
\hline & $\begin{array}{l}\text { No of } \\
\text { discharges }\end{array}$ & $\begin{array}{l}\text { Mean } \\
\text { length of } \\
\text { stay (days) }\end{array}$ & $\begin{array}{l}\text { Mean age } \\
\text { at admission } \\
\text { (yr) }\end{array}$ & $\begin{array}{l}\text { No of } \\
\text { discharges }\end{array}$ & $\begin{array}{l}\text { Mean } \\
\text { length of } \\
\text { stay (days) }\end{array}$ & $\begin{array}{l}\text { Mean age } \\
\text { at admission } \\
(y r)\end{array}$ \\
\hline $\begin{array}{l}1980 \\
1981 \\
1982 \\
1983 \\
1984 \\
1985 \\
1986 \\
1987 \\
1988 \\
1989 \\
1990 \\
1991 \\
1992 \\
1993\end{array}$ & $\begin{array}{rr}7 & 377 \\
7 & 626 \\
8 & 504 \\
8 & 917 \\
9 & 143 \\
9 & 927 \\
10471 \\
11085 \\
11472 \\
11698 \\
12420 \\
12522 \\
12432 \\
13022\end{array}$ & $\begin{array}{l}19 \cdot 1 \\
18 \cdot 9 \\
18 \cdot 4 \\
17 \cdot 4 \\
17 \cdot 1 \\
16 \cdot 6 \\
16 \cdot 7 \\
16 \cdot 3 \\
16 \cdot 1 \\
15 \cdot 4 \\
15 \cdot 0 \\
14 \cdot 8 \\
14 \cdot 4 \\
14 \cdot 0\end{array}$ & $\begin{array}{l}71 \cdot 2 \\
71 \cdot 5 \\
71 \cdot 6 \\
71 \cdot 8 \\
72 \cdot 1 \\
72 \cdot 1 \\
72 \cdot 1 \\
71 \cdot 9 \\
72 \cdot 1 \\
72 \cdot 2 \\
72 \cdot 1 \\
72 \cdot 2 \\
72 \cdot 1 \\
72 \cdot 5\end{array}$ & $\begin{array}{rr}7 & 064 \\
7 & 382 \\
7 & 868 \\
8 & 445 \\
9 & 113 \\
9 & 501 \\
10143 \\
10348 \\
10849 \\
11308 \\
11548 \\
12015 \\
11936 \\
12944\end{array}$ & $\begin{array}{l}24 \cdot 3 \\
22 \cdot 7 \\
22 \cdot 5 \\
21 \cdot 5 \\
20 \cdot 6 \\
19 \cdot 9 \\
19 \cdot 7 \\
19 \cdot 0 \\
19 \cdot 5 \\
18 \cdot 5 \\
18 \cdot 0 \\
17 \cdot 5 \\
16 \cdot 9 \\
16 \cdot 4\end{array}$ & $\begin{array}{l}75 \cdot 0 \\
75 \cdot 3 \\
75 \cdot 6 \\
75 \cdot 8 \\
76 \cdot 0 \\
76 \cdot 4 \\
76 \cdot 9 \\
76 \cdot 6 \\
76 \cdot 8 \\
76 \cdot 9 \\
76 \cdot 9 \\
76 \cdot 8 \\
76 \cdot 9 \\
77 \cdot 4\end{array}$ \\
\hline
\end{tabular}

Source: SIG Health Care Information.

Figure 1 Age adjusted discharge rates for heart failure in men (solid line) and women (broken line) in the Netherlands,

1980-1993. Source: SIG

Health Care Information.

The "new" European

Standard Population was used as a standard.

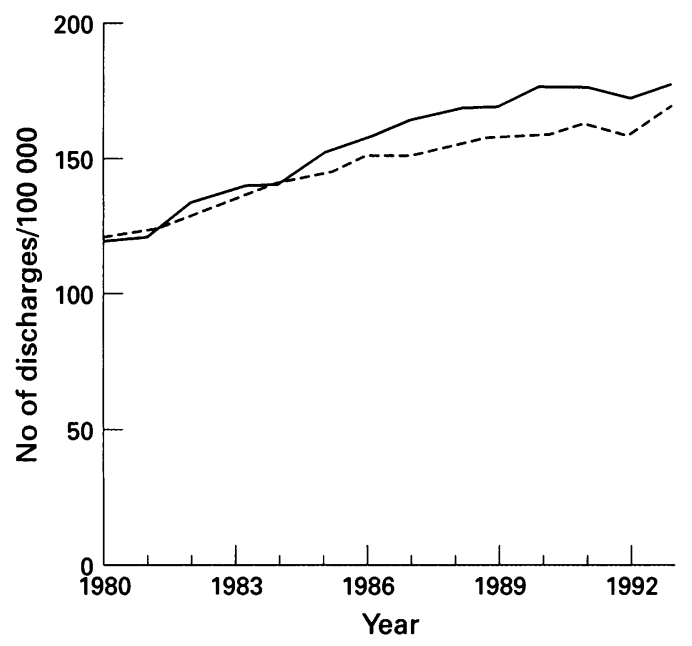

To calculate the average age at admission we assumed that all persons were admitted at, on average, the midpoint of each five year age category. Age adjusted discharge rates were calculated by direct standardisation using the "new" European Standard Population as a standard. ${ }^{11}$ Tests for linear trend were performed with Poisson regression. ${ }^{12}$

Furthermore, because the registry does not provide data on individual patients, we conducted a survey to obtain individual records of

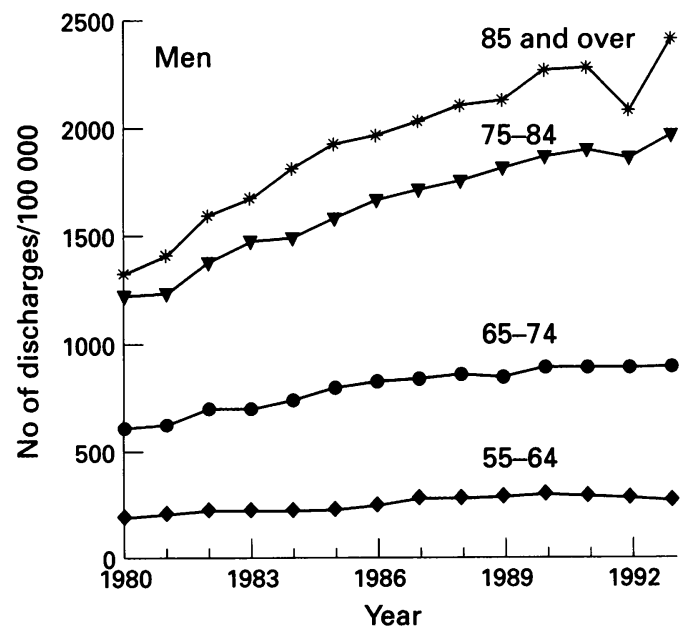

Figure 2 Age specific discharge rates for heart failure in men in the Netherlands, 1980-1993. Source: SIG Health Care Information. patients with heart failure to estimate the contribution and timing of readmissions. Seven hospitals (two university and five general) participated on a voluntary basis. This survey spanned a two year period from 1991 to 1992 and covered $6.3 \%$ of all hospital admissions for heart failure in that period. Time to readmission was analysed using Kaplan-Meier curves. Separate curves for readmission were constructed in patients with one, two, or three previous hospital admissions, respectively. End points were the dates of readmission and the starting points were the dates of discharge. Patients who died during their stay in the hospital were excluded from the subsequent readmission analysis.

\section{Results}

Table 1 lists the total number of discharges for heart failure, the mean length of stay, and the mean age at admission. The total number of hospital discharges for heart failure rose from 7377 in 1980 to 13022 in 1993 for men, and from 7064 to 12944 for women. The contribution of heart failure to the total number of hospital discharges in the Netherlands in 1993 was $1.7 \%$. The International Classification of Disease code 428 (heart failure) was by far the most common $(98.8 \%$ in 1993$)$ of the codes we combined for this study. The average age at admission increased slightly during the study-period (table 1). On average women were 4.5 years older than men. There was a marked and steady increase in the age adjusted discharge rates for both men and women (fig 1). From 1980 to 1993 the age adjusted discharge rates for heart failure increased by $48 \%$ in men and by $40 \%$ in women. Analysis of age specific discharge rates showed that the rise in the number of discharges was more pronounced in the older age groups (figs 2 and 3 ). The test of trend was significant $(P<0.05)$ in all age groups. In every age group the risk of hospital admission was higher for men than for women.

In 1993 the average length of hospital admission for patients with heart failure was

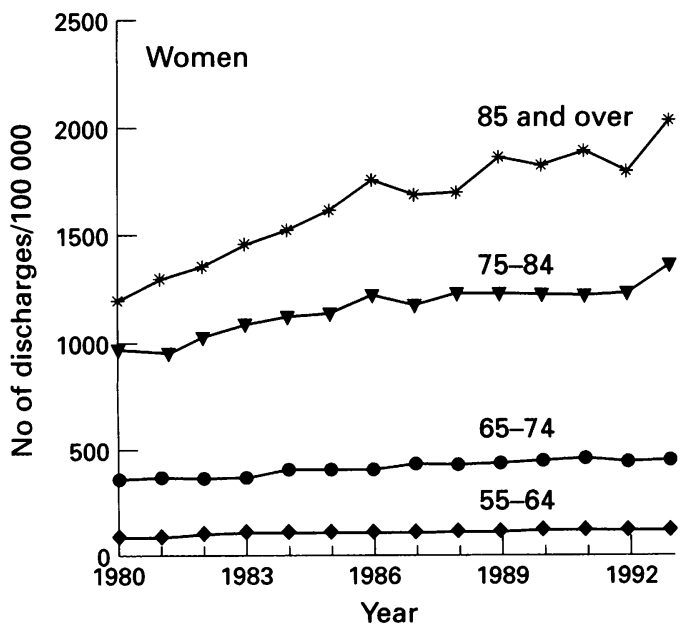

Figure 3 Age specific discharge rates for heart failure for women in the Netherlands, 1980-1993. Source: SIG Health Care Information. 
Table 2 Length of hospital admission (days) for heart failure in the Netherlands by age and gender in 1980, 1984, 1988, and 1993

\begin{tabular}{|c|c|c|c|c|c|c|}
\hline \multirow[b]{2}{*}{ Year } & \multicolumn{3}{|c|}{ Men age group in years } & \multicolumn{3}{|c|}{ Women age group in years } \\
\hline & $<60$ & $60-80$ & $80+$ & $<60$ & $60-80$ & $80+$ \\
\hline $\begin{array}{l}1980 \\
1984 \\
1988 \\
1993\end{array}$ & $\begin{array}{l}17 \cdot 8 \\
15 \cdot 1 \\
15 \cdot 1 \\
13 \cdot 4\end{array}$ & $\begin{array}{l}19.1 \\
16.9 \\
15.9 \\
13.8\end{array}$ & $\begin{array}{l}19.9 \\
18.4 \\
17 \cdot 1 \\
14.8\end{array}$ & $\begin{array}{l}20.8 \\
16.8 \\
16.4 \\
14.0\end{array}$ & $\begin{array}{l}24 \cdot 2 \\
20 \cdot 3 \\
19 \cdot 2 \\
16 \cdot 0\end{array}$ & $\begin{array}{l}25 \cdot 1 \\
21 \cdot 7 \\
20 \cdot 1 \\
17 \cdot 1\end{array}$ \\
\hline
\end{tabular}

Source: SIG Health Care Information.

14.0 days for men and 16.4 days for women. The length of hospital stay declined steadily from 21.6 days in 1980 to $15 \cdot 2$ days in 1993 . Slightly longer hospital admission times were observed with increasing age (table 2). In all age groups women stayed longer in the hospital than men, on average 1.6 days. During the study period the difference in length of stay between men and women decreased.

$15 \cdot 3 \%$ of all patients with a principal discharge diagnosis of heart failure in 1993 died in the hospital. In-hospital mortality was strongly age related. After stratification for age, in-hospital mortality for men was higher than for women in all age groups (fig 4). During the study period age adjusted inhospital mortality decreased from $19.9 \%$ in 1980 to $15.5 \%$ in 1993 in men, and from $17 \cdot 8 \%$ to $14.9 \%$ in women.

The survey conducted in seven hospitals for the years 1991 and 1992 yielded 3090 admissions with a first-listed discharge diagnosis of heart failure in 2440 patients. This corresponds to a $6 \cdot 3 \%$ sample of all hospital admissions for heart failure in the Netherlands in that period. The inclusion of hospital admissions with a discharge diagnosis of heart failure in any position would have increased the number by $86 \%$ from 3090 to 5740 . Within the two year period $18 \%$ of the patients were admitted more than once and 5\% more than twice. The percentage of patients readmitted for heart failure within six months after their first discharge was $14 \%$ (95\% CI $13 \%$ to $16 \%$ ). Of all patients discharged (alive) after their second hospital admissions 26\% (95\% CI $21 \%$ to $30 \%$ ) and of all patients discharged after their third hospital admissions $34 \%(95 \%$ CI $25 \%$ to $43 \%$ ) were readmitted within six months (fig 5).

Figure 4 Age specific inhospital mortality for heart failure in 1993 in men and women. Source: SIG Health Care Information.

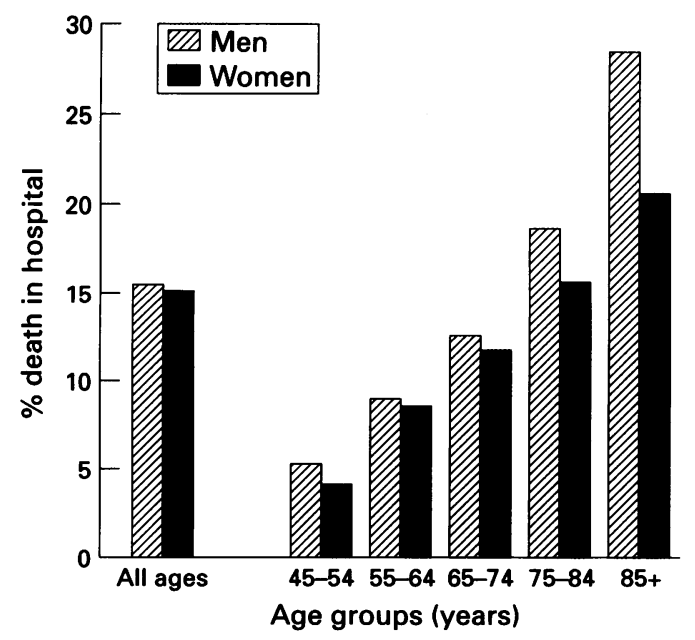

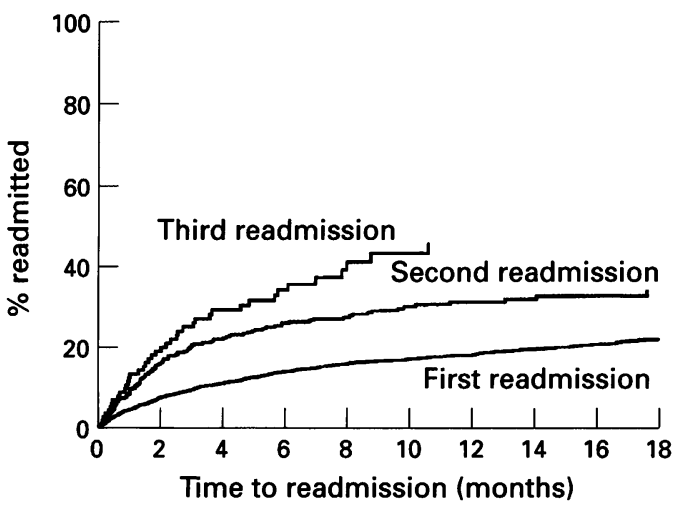

Figure 5 Separate curves (Kaplan-Meier) of the time to readmission for heart failure in patients with one, two, and three previous hospital admissions for heart failure.

Individual data on 2440 patients from a survey in seven hospitals during a two year period. Men and women combined.

\section{Discussion}

This study shows a pronounced increase in age adjusted discharge rates for heart failure for both men and women in the Netherlands during the past 14 years. Similar increases have been reported in the United States of America, Sweden, and Scotland. . $^{5}$ Compared with Scotland there was a difference in the absolute rate (1990: 212/100 000 in Scotland versus $160 / 100000$ in the Netherlands), but time trends were very similar. From 1980 to 1990 the crude discharge rate in Scotland increased $63 \%$, compared with $57 \%$ in the Netherlands. ${ }^{8}$ Explanations for the discrepancy in absolute rate could be differences in the age structure of the two countries, differences in admission policy, differences in the place of heart failure among the list of discharge diagnoses, and a true difference in prevalence of heart failure between the two countries.

We will discuss three possible explanations for the rise in age adjusted discharge rates for heart failure. These are an increase in the incidence of heart failure, the longer survival of heart failure patients, and changes in admission policy and coding practice.

INCREASE IN INCIDENCE OF HEART FAILURE? Hospital statistics can not be used as a measure of incidence of heart failure per se, although an increase in incidence of heart failure in the general population should eventually be reflected in higher hospital admissions rates. For an estimate of the prevalence and incidence of heart failure in the general population other types of studies are needed.

The two main causes of heart failure in the western world are coronary heart disease and hypertension. ${ }^{13}$ Mortality from coronary heart disease in the Netherlands started to decline in the early seventies and continued to do so, as in many other Western countries. ${ }^{14-16}$ It is believed that this decline is caused by a decrease in incidence as well as by improved survival of patients with coronary heart disease. ${ }^{17}$ Data from the Framingham study suggest that one third of the decline in coronary heart mortality was caused by a decline in inci- 
dence and two thirds by a lower case fatality. ${ }^{1819}$ If this scenario is true it will eventually lead to an increase in the number of patients with chronic heart disease, including heart failure. ${ }^{9}$ The recent, widespread use of thrombolysis will probably further improve the survival after acute myocardial infarction, but at the same time will increase the number of patients having an impaired cardiac reserve/left ventricular function who are therefore at a higher risk of developing heart failure. ${ }^{1720}$

As in the United States there has been a decline in prevalence of hypertension in the Netherlands during the last decades, ${ }^{21}$ making it an unlikely contributor to the suggested increase in incidence of heart failure. However, from 1987 the percentage of people treated for hypertension has started to decline in the Netherlands, ${ }^{22}$ unlike the United States of America where a steady increase was observed over the past three decades. ${ }^{23}$ The importance of the control of hypertension in the prevention of heart failure remains uncertain. Yusuf et al argued that the treatment of hypertension does not prevent heart failure, but merely postpones its onset. ${ }^{24}$

\section{LONGER SURVIVAL OF PATIENTS WITH HEART FAILURE?}

During the past decade several advances have been made in the treatment of heart failure, ${ }^{25}$ most recently the introduction of angiotensinconverting enzyme (ACE) inhibitors. Although a recent meta-analysis demonstrated an impressive $23 \%$ reduction in mortality in trials of ACE inhibitors in heart failure, the gain in life expectancy is measured in months rather than years. ${ }^{26}$ Furthermore, because it takes time to translate observed benefits in clinical trials to larger groups of heart failure patients, ${ }^{27}$ ACE inhibitors are unlikely to have had a substantial effect on survival during our study period. The Framingham Heart Study for example did not find an improvement in survival after the onset of heart failure in the period 1948-1988. ${ }^{3}$ Obviously, this does not exclude that the possibility that increasing opportunities for tailor-made treatment of patients with severe heart failure have resulted in an increase in hospital admissions.

\section{CHANGES IN ADMISSION POLICY AND CODING PRACTICE?}

The number of hospital admissions is directly influenced by changes in admission policy and coding practice. Unfortunately, these changes are difficult to quantify. The growing attention focused on heart failure by physicians and the progress in the pharmacotherapy of heart failure could have led to more patients, especially the elderly, being admitted to hospital. In addition, the more widespread use of echocardiography has made confirmation of heart failure in its earlier stages easier. Given the constraints on the health care budget it is unlikely that those with the milder forms of heart failure are admitted to hospital more often. Few studies have been done to evaluate the quality of the coding process. A recent survey in the Netherlands indicated that $80 \%$ of the patients discharged with ICD code 428 (heart failure) fulfilled the Framingham criteria for heart failure. ${ }^{28}$

Heart failure is characterised by long hospital admissions times and frequent readmissions. This adds to the importance of heart failure in terms of costs. Despite a continuous decrease, the average length of stay for heart failure is still appreciably longer than for acute myocardial infarction (15.2 days compared with 11.6 days in 1993).

Within a two year period $18 \%$ of the patients were admitted more than once. The proportion of patients that returned to the hospital increased with every new admission (fig 5). Our survey yielded a conservative estimate of the number of readmissions in patients with heart failure. First of all, readmissions to a different hospital could not be detected. Secondly, admissions before our fixed time period (1991-1992) were not taken into account. Therefore, admissions marked as a first admission in our survey might really have been readmissions.

In conclusion, age adjusted discharge rates for heart failure in the Netherlands increased by $48 \%$ for men and by $40 \%$ for women in the period 1980 to 1993. Readmissions within a short period of time are a typical feature of heart failure patients.

In view of the expected rise in the number of persons above the age of 65 years and the progress in medical care a further increase in the number of hospital admissions for heart failure is likely. More efforts are needed to prevent and delay the development of heart failure in high risk patients, and more research is needed into the factors influencing the decision to (re)admit patients with heart failure to hospital. ${ }^{29}$

This work was supported by a grant from the Netherlands Heart Foundation (grant no 42.012).

For this project an advisory committee was installed by the Netherlands Heart Foundation. We are indebted to the members of this committee for their helpful comments during the bers of this committee 10 aration of the paper.
prepar

1 Cowie MR, Mosterd A, Wood DA, Deckers JW, Sutton GC, Poole-Wilson PA, et al. The epidemiology of heart failure. Eur Heart $\mathcal{f}$ (in press).

2 Koopmanschap MA, van Roijen L, Bonneux L. Costs of diseases in The Netherlands [in Dutch]. Report of the diseases in The Netherlands [in Dutch]. Report of the Institute for Medical Technology Assessment. Erasmus University, Rotterdam, 1992.

3 Ho KKL, Anderson KM, Kannel WB, Grossman W, Levy $D$. Survival after the onset of congestive heart failure in Framingham Heart Study subjects. Circulation 1993;88: 107-15.

4 The Task Force on Heart Failure of the European Society of Cardiology. Guidelines for the diagnosis of heart failure. Eur Heart $\mathcal{f}$ 1995;16:741-51.

5 Eriksson H, Wilhelmsen L, Caidahl K, Svardsudd K. Epidemiology and prognosis of heart failure. Z Kardiol Epidemiology and pro

6 Gillum RF. Heart failure in the United States 1970-1985. Am Heart f 1987;113:1043-5.

7 Ghali JK, Cooper R, Ford E. Trends in hospitalisation rates for heart failure in the United States, 1973-1986. Arch Intern Med 1990;150:769-73.

8 McMurray J, McDonagh T, Morrison CE, Dargie HJ. Trends in hospitalisation for heart failure in Scotland 1980-1990. Eur Heart $₹$ 1993;14:1158-62.

9 Bonneux L, Barendregt J, Meeter K, Bonsel GJ, van der Maas PJ. Estimating clinical morbidity due to ischemic heart disease and congestive heart failure: the future rise of heart failure. Am $\mathcal{F}$ Public Health 1994;84:20-8.

10 International Classification of Diseases (9th revision) Clinical modification, 4th ed. Washington: US Department of Health and Human Services, 1991 .

11 World Health Organization. World Health Statistics Annual 1992. World Health Organization, Geneva 1993: XXII. 
12 Breslow NE, Day NE. Fitting models to grouped data. In: Statistical methods in cancer research. Volume II: the design and analysis of cohort studies. New York: Oxford University Press, 1987

13 Teerlink JR, Goldhaber SZ, Pfeffer MA. An overview of contemporary etiologies of congestive heart failure. $\mathrm{Am}$ Heart f 1991;121:1852-3.

14 Hoogendoorn $D$. Atherosclerotic diseases of the heart in hospitals and in the statistics of causes of death [in Dutch]. Ned Tijdschr Geneeskd 1985;129:1827-33.

15 Hoogendoorn D. Observations on the current status concerning the epidemic of acute myocardial infarction [in cerning the epidemic of acute myocardial infa

16 Hoogendoorn D. With decreasing mortality does the incidence of acute myocardial infarction decrease also? [in Dutch]. Ned Tijdschr Geneeskd 1990;134:1896-900.

17 McGovern PG, Pankow JS, Shahar E, Doliszny KM, Folsom AR, Blackburn $\mathrm{H}$, et al. Recent trends in acute coronary heart disease. Mortality, morbidity, medical care, and risk factors. N Engl F Med 1996:334:884-90.

18 Sytkowski PA, Kannel WB, D'Agostino RB. Changes in risk factors and the decline in mortality from cardiovascular disease. The Framingham heart study. $N$ Engl $f$ Med 1990;322:1635-41.

19 Goldman L, Cook EF. The decline in ischemic heart disease mortality rates. An analysis of the comparative effects of medical interventions and changes in lifestyle. Ann Intern Med 1984;101:825-36.

20 Stevenson $R$, Ranjadayalan $K$, Wilkinson $P$, Roberts $R$, Timmis AD. Short and long term prognosis of acute
Timson myocardial infarction since introduction of thrombolysis. $B M \mathcal{1 9 9 3 ; 3 0 7 : 3 4 9 - 5 3 .}$
21 van de Mheen PJ, Bonneux L, Gunning-Schepers LJ. Variation in reported prevalences of hypertension in The Netherlands: the impact of methodological variables. $\mathcal{f}$ Epidemiol Commun Health 1995;49:277-80.

22 van Leer EM, Verschuren WMM, Kromhout D. Trends in blood pressure and the prevalence and treatment of hypertension in young adults in the Netherlands. Eur $f$ Epidemiol 1994;10:151-8.

23 Joint National Committee on Detection, Evaluation, and Treatment of High Blood Pressure. The fifth report of the Joint National Committee on Detection, Evaluation, the Joint National Committee on Detection, Evaluation, and Treatment of High Blood $1993 ; 153: 154-83$.

24 Yusuf S, Thom T, Abbott RD. Changes in hypertension treatment and in congestive heart failure mortality in the United States. Hypertension 1989;13(suppl I):I74-I79.

25 Armstrong PW, Moe GW. Medical advances in the treatment of congestive heart failure. Circulation 1993;88: 2941-52.

26 Garg R, Yusuf S. Overview of randomized trials of angiotensin-converting enzyme inhibitors on mortality and morbidity in patients with heart failure. $¥ A M A 1995$; 273:1450-6.

27 Anonymous. Failure to treat heart failure (editorial). Lancet 1992;339:278-9.

28 Heerdink ER. Clustering of drug use in the elderly. Population based studies into prevalences and outcomes. Population based studies into prevalences and outco

29 Rich MW, Beckham V, Wittenberg C, Leven CL, Freedland KE, Carney RM. A multidisciplinary intervention to prevent the readmission of elderly patients with congestive heart failure. $N$ Engl $\mathcal{F}$ Med 1995;333:1190-5. 